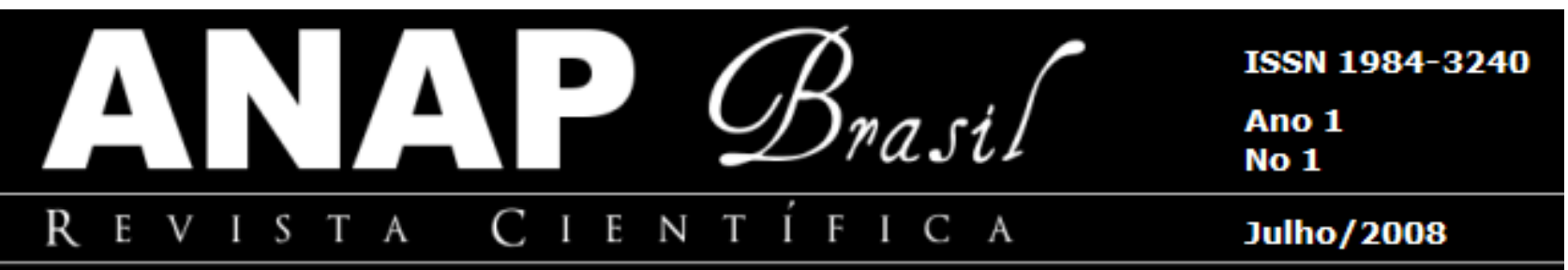

\title{
A GESTÃO DOS RECURSOS HÍDRICOS SOB A PERSPECTIVA DA DESCENTRALIZAÇÃO
}

\section{Edenis César de Oliveira ${ }^{1}$}

RESUMO: As discussões e os debates sobre o meio ambiente em geral e a iminente escassez da água em particular, têm estado na pauta de trabalho de muitos pesquisadores, cientistas, acadêmicos, líderes empresariais, governo e da comunidade como um todo. As publicações da literatura na área em questão têm apresentado um crescente índice e atestam este fato. A maioria esmagadora desses conceituados estudos afirma que caminhamos para um ponto de colapso e estrangulamento caso nada seja feito para reverter esse quadro alarmante. A água, como bem imprescindível à vida, tem ganhado um destaque nesse meio, uma vez que, falar de água é falar de vida. Diante disso, a crescente necessidade de se obter água na quantidade e na qualidade desejadas para seus múltiplos usos exige planejamento e coordenação de ações. O grande desafio, entretanto, é promover um gerenciamento que compreenda em todo seu arcabouço o trinômio integração-descentralização-participação, como forma de sustentação e consolidação de todo processo. Este trabalho propõe, a partir de uma revisão bibliográfica, apresentar, inicialmente uma breve contextualização da água, seguido por uma explanação da gestão de recursos hídricos no Brasil, mormente seus principais aspectos, encerrando com algumas considerações sobre a descentralização e suas principais ocorrências, como parte do funcionamento de todo o processo.

Palavras-chave: Gestão de recursos hídricos. Água. Descentralização.

\section{INTRODUÇÃO}

\footnotetext{
${ }^{1}$ Coordenador do Curso de Administração da Fundação Gammon de Ensino; Administrador de Empresas, especialista em Gestão Empresarial, mestrando em Geografia Humana na linha de pesquisa Gestão Ambiental e Dinâmica Socioespacial pela FCT/UNESP campus de Presidente Prudente/SP. e-mail: edenis@netonne.com.br
} 


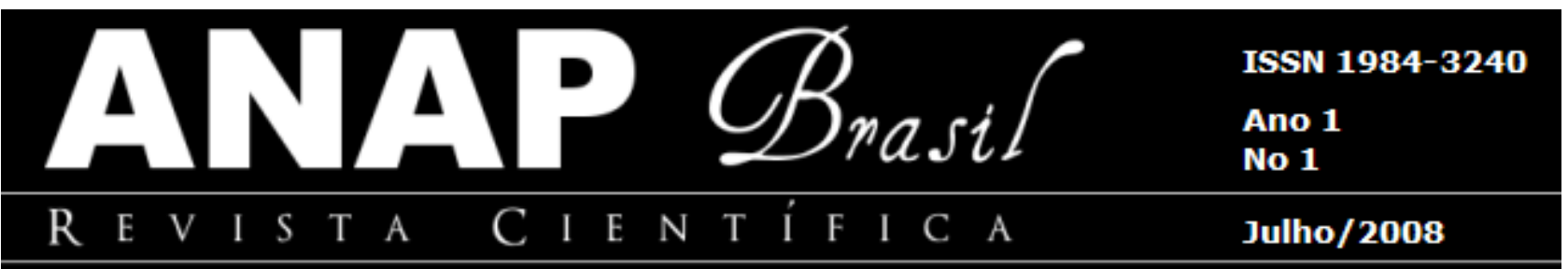

Nosso futuro e o de nossas famílias [...] dependerá menos do desenvolvimento econômico e tecnológico do que da capacidade das sociedades humanas de formular e administrar determinadas regras, instituições e meios de ação que Ihes permitam viver juntos em um mundo interdependente, com todas as suas complexidades e limitações, sua diversidade e sua fragilidade (PETRELLA, 2002).

A questão relativa à água se apresenta como determinante da capacidade e necessidade premente da sociedade de se constituir um pacto, um código de conduta, que implique numa nova maneira de perceber esta questão, envolvendo todos, sem nenhuma exceção, uma vez que todos dependem dela para a sobrevivência.

A água representa insumo de fundamental importância à vida, responsável pelo equilíbrio ambiental, configurando elemento insubstituível em diversas atividades humanas (SETTI et all, 2001), além de ser considerado fator estratégico para o desenvolvimento econômico e a melhoria da qualidade de vida (AZEVEDO \& PEREIRA, 2006, p. 11).

O célere crescimento populacional somado ao vertiginoso desenvolvimento tecnológico, notadamente no período pós Revolução Industrial, aumentou e tem aumentado consideravelmente a demanda por este bem tão precioso e imprescindível à vida. Como conseqüência, evidencia-se, em várias regiões do mundo e até mesmo em nosso país, problemas crônicos de escassez de água.

$\mathrm{Na}$ realidade, tanto o crescimento quanto o adensamento populacional não são os únicos responsáveis pela escassez relativa da água, afirma Thame (2004).

Para este autor:

Esgotos domésticos e industriais, lixões, entulho, desmatamento, ocupação e impermeabilização das margens dos rios têm deixado a água indisponível para consumo humano, notadamente nas regiões mais densamente povoadas. Tanto ou mais que o crescimento da população, estas são fortes razões da escassez de água (THAME, 2004, p. 264).

No caso específico do Brasil, a demanda pelo recurso cresce exponencialmente. À medida que cresce a população, que se expande o parque industrial, que aumenta a área de irrigação, a demanda sofre um forte e expressivo impacto.

Diante desse cenário, uma coisa é certa: precisa-se de quantidades cada vez maiores de água e a única fórmula que se conhece, pelo menos até agora, para se 


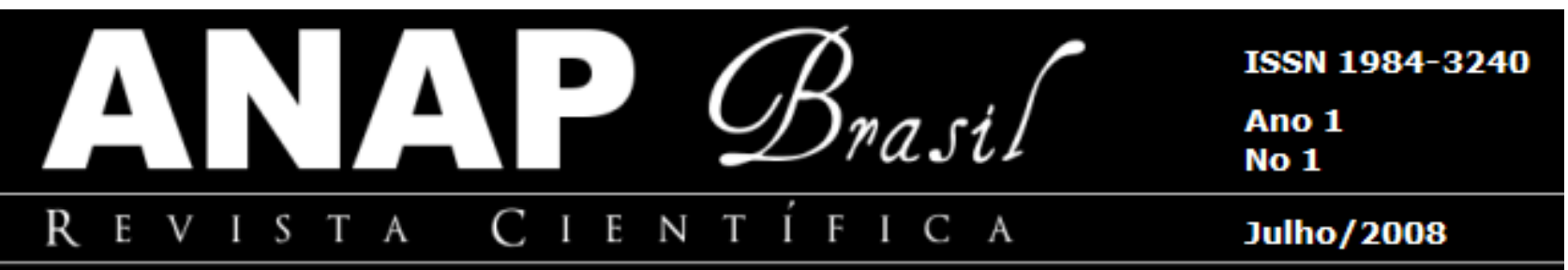

conseguir uma situação de equilíbrio entre a oferta e a demanda na área em questão é substituir totalmente a idéia tradicional de que a solução é aumentar sua oferta pela visão de uso mais eficiente (REBOUÇAS, 2004).

Ainda Rebouças (2004, p. 42) enfatiza:

\begin{abstract}
Desse modo, o Brasil tem muita água, mesmo no Nordeste. Porém, o seu uso cada vez mais eficiente desempenhará, certamente, um papel vital na saúde atual e futura da nossa sociedade e na produção de alimentos, principalmente. $O$ uso eficiente da água dos rios do Brasil significa a possibilidade de suprir as necessidades humanas básicas, sem destruir o meio ambiente, a qualidade da água, garantir o crescimento econômico e social com proteção ambiental.
\end{abstract}

Para este autor, no caso exclusivo do Brasil, há água suficiente para o atendimento das necessidades básicas, inclusive na região semi-árida, bastando a substituição dos procedimentos tradicionalmente utilizados por outros que sejam mais eficazes no sentido de minimizar os atuais índices de consumo.

A decisão e opção pelo uso mais eficiente dos recursos naturais em geral e da água em particular deve-se dar de maneira integrada e associada aos instrumentos de gestão em todos os níveis competentes. Só assim será possível alcançar um patamar que possibilite uma adequação da oferta e da demanda com vistas ao uso racional desse recurso tão precioso.

Segundo o documento Population Reference Bureau (1997) ${ }^{2}$ apud Setti et all (2001), atualmente mais de 1 bilhão de pessoas vivem em condições de insuficiência no que diz respeito à disponibilidade de água para consumo. Não obstante este quadro já caótico, ainda, segundo estes autores, "em 25 anos, cerca de 5,5 bilhões de pessoas estarão vivendo em áreas com moderada ou séria falta de água".

Christofidis (2006) considera que, caso a população mundial aumente para 10 bilhões de pessoas nos próximos cinqüenta anos, $70 \%$ desses habitantes do planeta enfrentarão deficiências no suprimento de água, conseqüentemente algo em torno de um bilhão e seiscentos milhões de pessoas que não terão água para obtenção da alimentação básica.

${ }^{2}$ POPULATION REFERENCE BUREAU. La dinâmica entre La población y El médio ambiente. Washington D.C. 1997. In: Demanboro, A. C. e Mariotoni, C. A. O conceito de escala e o desenvolvimento sustentável, implicações sobre os recursos hídricos e energéticos. Revista Brasileira de Energia, v. 7, n. 2, Rio de Janeiro, 1999. 


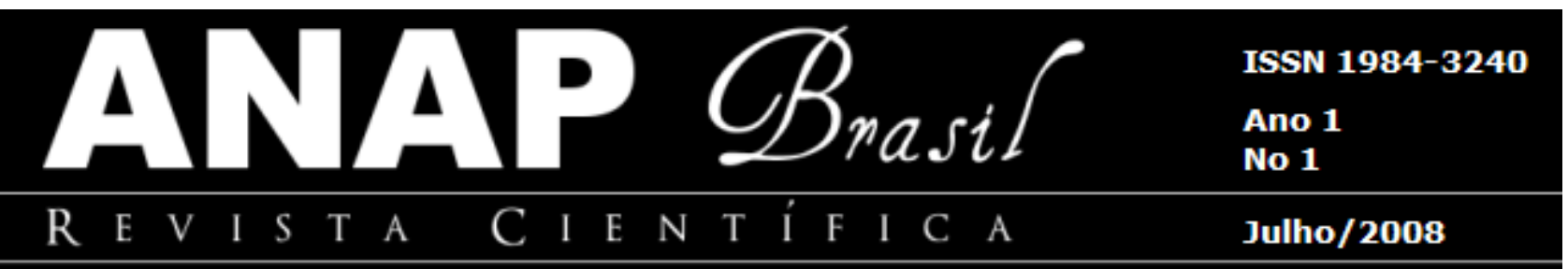

Outro ponto que precisa ser levado em consideração é a questão ainda predominante da cultura da abundância. Culturalmente, parece vaga a concepção de escassez de água, sustentada, talvez, pela regular disponibilidade em nosso país, sobretudo nas regiões mais avançadas. Entretanto, esta é uma concepção que, há algum tempo vem sendo denunciada e combatida por renomados estudiosos e especialistas preocupados com a questão.

A idéia de abundância deste bem social serviu durante muito tempo como suporte à cultura do desperdício, a não realização dos investimentos necessários para seu uso e proteção mais eficientes, e à sua baixa e insignificante valorização econômica (SETTI et all, 2001).

Nas palavras de Tundisi (2005):

\footnotetext{
É falsa a aparente concepção de que a água doce é abundante. Somente $3 \%$ da água do planeta é disponível como água doce. Destes $3 \%$, cerca de $75 \%$ estão congelados nas calotas polares e cerca de $10 \%$ estão reservados nos aqüíferos. Portanto, somente $15 \%$ dos $3 \%$ de água doce do planeta estão disponíveis.
}

De acordo com Setti et all (2001) o Brasil ocupa uma posição privilegiada face a maioria dos países no que tange ao seu volume de recursos hídricos. No entanto, $73 \%$ da água doce disponível do país encontra-se na Bacia Amazônica, habitada apenas por $4,3 \%$ da população, sendo que apenas $27 \%$ dos recursos hídricos brasileiros estão disponíveis para mais de $95 \%$ da população.

Diante disso é possível constatar a perda da condição do país em permanecer nesta condição de despreocupação. A irregularidade na distribuição requer um dinamismo altamente eficaz na gestão dos recursos hídricos.

2 VISÃO PANORÂMICA DO USO E GESTÃO DOS RECURSOS HÍDRICOS NO BRASIL

\subsection{O CÓDIGO DAS ÁGUAS}




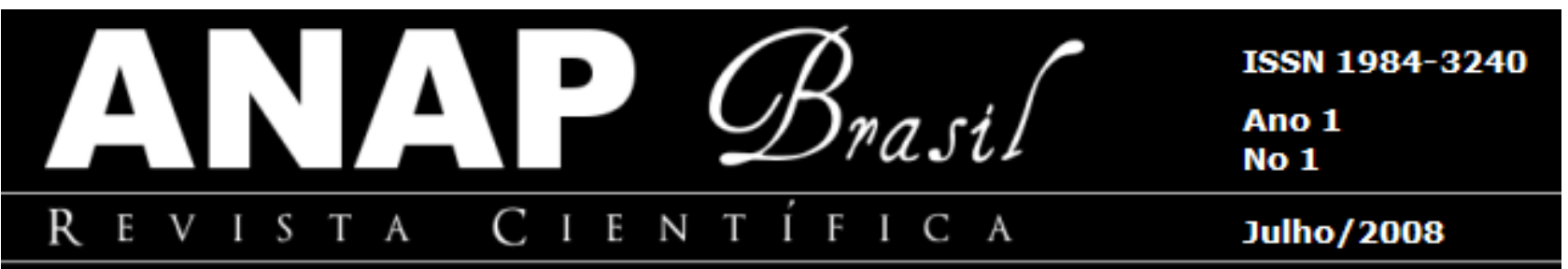

O projeto que propunha a criação do Código das Águas foi elaborado no ano de 1907, posteriormente encaminhado à Câmara dos Deputados, ficou em tramitação por quase três décadas. As razões pelas quais se justifica esse longo período de adiamento e tramitação foram sua inadequação aos dispositivos constitucionais então vigentes e os problemas relacionados às secas no semi-árido nordestino (ASSUNÇÃO e BURSZTYN, 2001).

Esse cenário mudaria substancialmente frente o quadro político institucional que emerge com a Revolução de 1930. Além da ruptura política e econômica com o Estado oligárquico, o novo projeto político apresentava como meta um esforço considerável de modernização técnica e administrativa do aparelho do Estado, além da gestão direta dos serviços públicos. A partir de então, começa a ser criado um arcabouço jurídicoadministrativo básico que serviria de base a gestão pública, atrelado a um sistema burocrático que passa a centralizar e administrar vários serviços antes terceirizados (SMA/CPLEA, 2004).

Importante destacar que esta década (1930) é caracterizada pela gênese da política ambiental brasileira, momento em que foi editada a legislação básica sobre o tema: o Código Florestal (Decreto 23.793, de 23 de janeiro de 1934); o Código de Minas (Decreto 24.642, de 10 de julho de 1934); o Código de Águas (decreto 24.643, de 10 de julho de 1934) e o Código de Pesca (Decreto 794, de 19 de outubro de 1938).

Segundo Moreira (2004), a opção do Brasil, desde 1934, com o Código das Águas, foi de que as águas do País fossem destinadas principalmente à geração de energia elétrica. Por isso, a administração do recurso cabia ao setor elétrico, o que, posteriormente, viria a causar certo desconforto, tendo em vista o fato de que o gerenciamento era feito por um usuário da água. Nessa dinâmica, o mesmo órgão que dava as concessões e controlava a energia elétrica era responsável pelo gerenciamento da água.

A regulação pública sobre os recursos naturais no Brasil, com início marcado no período pós revolução de 1930, teve como característica o fato de ter o controle federal sobre a ocupação do território e sobre os usos dos recursos naturais. A própria Constituição de 1934 ao estabelecer os critérios para a exploração dos recursos hídricos, define como competência da União legislar sobre o tema. 


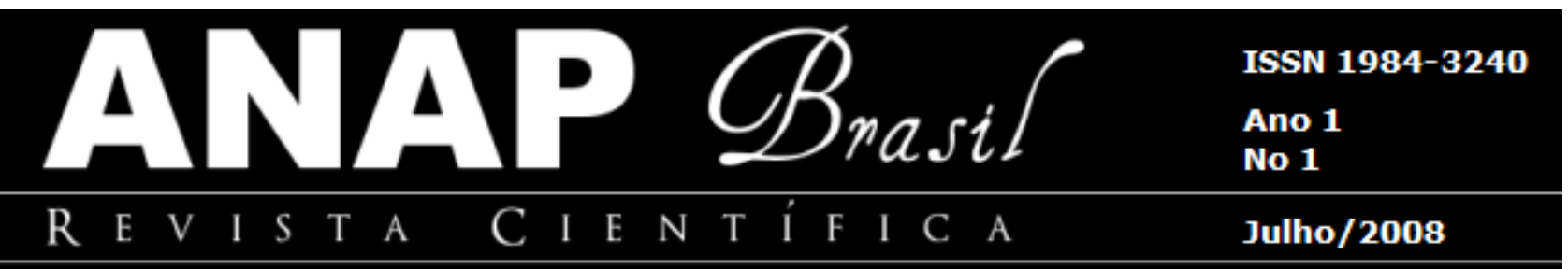

O Código das Águas, instituído em 1934, reflete esse amplo processo de centralização e regulação através de regras de controle:

O Código de Águas tinha como objetivo geral, estabelecer regras de controle federal para o aproveitamento dos recursos hídricos, principalmente para fins energéticos. Por outro lado, o código também formulava alguns princípios que podem ser considerados um dos primeiros instrumentos de controle do uso de recursos hídricos no país e a base para a gestão pública do setor de saneamento, sobretudo no que se refere à água para abastecimento (SILVA, 1998, p. 59-60).

Esse sistema consubstanciado a um formato centralizador perdurou até a década de 1980, quando se intensificaram os conflitos, colocando em questão a necessidade de uma maior integração entre as várias esferas de governo como possibilidade mais viável para enfrentar as questões atinentes ao federalismo. Diante disso, municípios, sociedade civil e usuários desencadearam ações no sentido de alcançar uma maior participação na gestão dos recursos hídricos, concomitantemente, a descentralização da política vigente (NOGUEIRA, [2001]).

A partir desta década, esse quadro começa a sofrer significativas alterações. Já no segundo ano desta década foi editada a Lei 6.938, que institui a Política Nacional de Meio Ambiente que, além de definir os vários instrumentos da política, criou também o Sistema Nacional de Meio Ambiente (Sisnama), formado pelos órgãos federais, pelas agências estaduais e municipais e, principalmente, pelo Conselho Nacional de Meio Ambiente (Conama), criado em 1984.

Dessa forma, essa configuração de Estado autoritário, caracterizado por uma gestão setorial norteada por princípios exclusivamente técnico-burocráticos e por níveis de decisão centralizados, somado ao aumento dos movimentos de resistência com vistas à construção de outra institucionalidade democrática constituiu-se em fatores que marcaram profundamente o quadro político brasileiro. Indubitavelmente, esses movimentos foram importantes para a consolidação das novas relações entre o Estado e a sociedade civil. "Sem dúvida, as últimas décadas da história do País têm assistido, cada vez mais, essa relação ser permeada pela idéia da participação e controle social na gestão da coisa pública" (SMA/CPLEA, 2004, p. 34). 


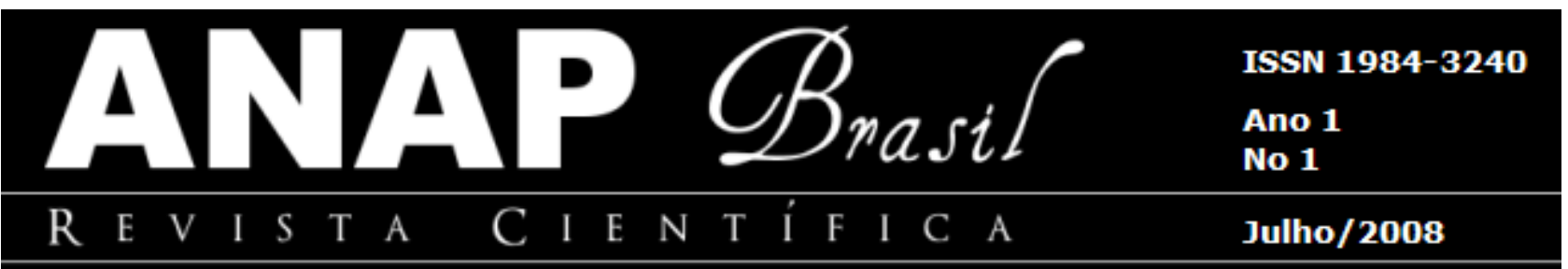

Por conseguinte, segundo SMA/CPLEA (2004), essa conjuntura altamente favorável de reconstrução das instituições democráticas, de surgimento dos movimentos populares e de criação de novas organizações da sociedade civil, somada às demandas dos cidadãos e usuários que clamavam pela qualidade e oferta de recursos hídricos para o abastecimento público, adicionado às manifestações dos técnicos e especialistas que, por meio de suas associações, lançaram as diretrizes que originariam e comporiam as bases que orientariam a nova política brasileira de recursos hídricos.

No entender de Novaes (2006) essa nova configuração, caracterizada como uma vertente descentralizadora tinha o respaldo e apoio crescentes da comunidade técnica engajada na defesa dos conceitos de gestão integrada e usos múltiplos das águas. Para este autor, "tal proposta enfrentava a oposição de atores que buscavam preservar o controle histórico do setor elétrico sobre a gestão das águas, defendendo, entre outras bandeiras, a concentração de poder no Departamento Nacional de Águas e Energia Elétrica (DNAEE), órgão do Ministério das Minas e Energia" (p. 52).

Pode-se afirmar que este processo de transição - de uma configuração centralizadora para um sistema descentralizado -, não foi tão simples de ser implementado e executado, aja visto a magnitude dos obstáculos institucionais, somado a um conjunto oculto, porém atuante, de interesses difusos com relação aos diversos atores envolvidos.

Nessa vertente, o desafio maior do sistema de gerenciamento dos recursos hídricos é o de conseguir fazer o pacto entre os diferentes atores (AMARAL, 1993).

2.1.2 A Lei das Águas: um novo marco legal e institucional

A aprovação da Lei 9.433, de 08 de janeiro de 1997, instituindo a Política Nacional de Recursos Hídricos e o Sistema Nacional de Recursos Hídricos, constitui o marco inicial de uma nova fase para os recursos hídricos brasileiros. Nela constam os cinco instrumentos considerados essenciais à gestão das águas: o Plano Nacional de Recursos Hídricos, a outorga do direito de uso dos recursos hídricos, a cobrança pelo uso da água, o enquadramento dos corpos d'água em classes de uso e o Sistema Nacional de Informações sobre os Recursos Hídricos, além dos quatro organismos institucionais do Sistema de Gerenciamento: o Conselho Nacional de Recursos Hídricos (CNRH), os 


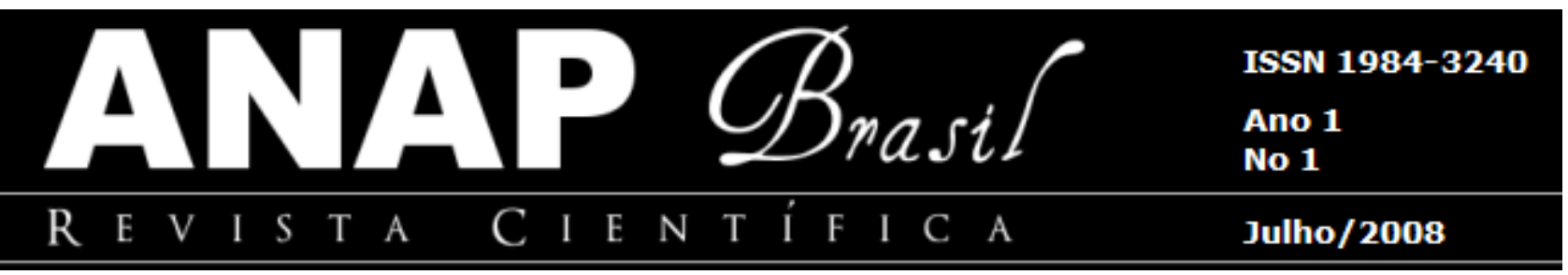

comitês de bacias hidrográficas, as agências de água e as organizações civis de recursos hídricos (BERBERT, 2003).

Cardoso (2003) considera a referida Lei como o ponto de partida no processo de consolidação no campo dos recursos hídricos no Brasil, instituindo-o como esfera autônoma. Para a autora, o papel e a importância estratégica da água foram redefinidos não só no âmbito das políticas públicas, mas para sociedade como um todo.

A Política Nacional de Recursos Hídricos está baseada nos seguintes fundamentos:

I. a água é um bem de domínio público;

II. a água é um recurso natural limitado, dotado de valor econômico;

III. em situações de escassez, o uso prioritário dos recursos hídricos é o consumo humano e a dessedentação de animais;

IV. a gestão dos recursos hídricos deve sempre proporcionar o uso múltiplo das águas;

V. a bacia hidrográfica é a unidade territorial para implementação da Política Nacional de Recursos Hídricos e atuação do Sistema Nacional de Gerenciamento de Recursos Hídricos;

VI. a gestão dos recursos hídricos deve ser descentralizada e contar com a participação do Poder Público, dos usuários e das comunidades.

No que tange ao fundamento I, o artigo 46 do Código das Águas já conferia ao recurso o tratamento de bem público; todavia, o enfoque jurídico que predominou durante a vigência do Código foi o enfoque privado, principalmente quanto ao uso da água com a finalidade de geração de energia elétrica, como mencionado anteriormente, em detrimento do enfoque público, cuja ênfase deveria estar no uso múltiplo (CAVINI, 2002).

Leal (2000) numa breve, porém importante interpretação contribui dizendo que, no tocante às águas públicas, estas, são de propriedade de toda população, cabendo ao Estado o dever de administrá-las, acrescentando o autor que este seria "o motivo pelo qual a outorga do direito de uso da água não foi transferida aos colegiados dos sistemas de gestão, permanecendo como função do Estado" (p. 44).

É cabível aqui a contribuição de Ferreira \& Ferreira (2006) ao afirmar que:

O fato da água constituir-se como um dos elementos e exercer indispensáveis funções quanto à sobrevivência da vida na terra e à 


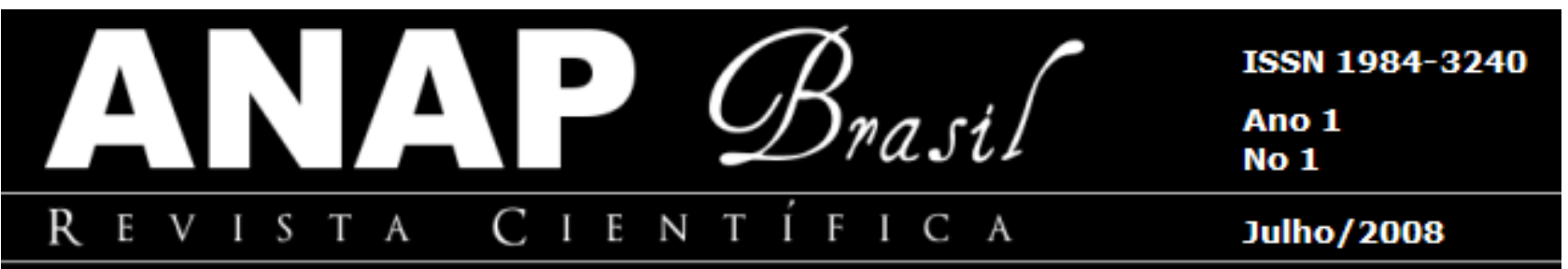

manutenção do equilíbrio ecológico, faz dela um bem de interesse difuso, recaindo sua titularidade sobre toda coletividade, sem qualquer forma de discriminação (p. 6).

Dessa forma, considera-se este recurso como não circunscrito a um único usuário, ou a um grupo de usuários ou determinado setor que seja. Sua titularidade recai sobre a coletividade e, por extrapolar a esfera de interesse individual de cada pessoa, justifica-se a intervenção do Estado como agente regulador.

O fundamento II trata diretamente da limitação da água, desaprovando a visão ainda prevalecente da abundância ou infinitude do recurso, bem como do seu uso indiscriminado. É preciso lembrar que, nesse ponto, a lei está se referindo à finitude da água, sobretudo no aspecto quantitativo. Todavia, o quadro se torna ainda mais alarmante, quando se considera a indisponibilidade de uso da água ocasionada pelo aspecto qualitativo, ou seja, o recurso existe, porém sem condições de uso.

Nas palavras de Leal (2000, p. 46) "a visão da finitude da água e de seu valor econômico são componentes básicos para construção da nova cultura hídrica, que se pretende implantar no país com a política e sistema nacional de gerenciamento de recursos hídricos".

Quanto ao fundamento III, há uma hierarquização por ordem decrescente de importância e priorização quanto ao uso da água, ressaltando a essencialidade da água para a vida. Em áreas consideradas críticas, com escassez de água, esse item assume papel crucial ao disciplinar o uso e evitar a preferência no atendimento a determinadas atividades econômicas em detrimento de outros usos considerados mais importantes, o que, segundo Leal (2000, p. 46) configuraria uma "condição anômala".

O fundamento IV pode ser considerado base da gestão dos recursos hídricos quando afirma que esta deve sempre proporcionar o uso múltiplo das águas, ou seja, sem privilégio de um usuário em detrimento de outro. Para Cardoso (2003) esse fundamento busca a "igualdade de condições".

A bacia hidrográfica reconhecida como unidade territorial para implementação da Política Nacional de Recursos Hídricos e atuação do Sistema Nacional de Gerenciamento de Recursos Hídricos, compreendida na lei como $5^{\circ}$ fundamento (fundamento $V$ ), consiste num importante passo dado pela Lei 9.433/97 uma vez que este recorte territorial possibilita relação direta com as questões econômicas, sociais e ambientais da população 


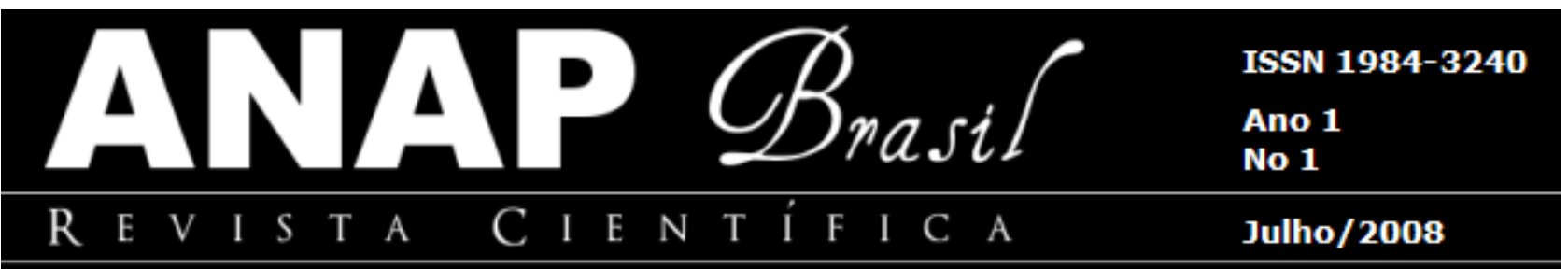

que a integra. Pode-se afirmar que se trata de uma verdadeira mudança cultural e estrutural na forma de pensar a dinâmica territorial (BARROS, $2002^{3}$ apud OLIVEIRA, 2007, p. 2).

A bacia hidrográfica é uma realidade física, mas é também um conceito socialmente construído. Passa a ser, portanto, um campo de ação política no que diz respeito à partilha de responsabilidades e de tomada de decisão (CUNHA \& GUERRA, 2003).

Assim, a compreensão de bacia hidrográfica como unidade geográfica pertinente para atender a objetivos propostos por organizações institucionais emergentes não se constitui apenas no reconhecimento do peso da dimensão ecológica, mas também das dimensões sociais, culturais e políticas na busca pela compreensão e proposição de medidas mitigadoras face à complexidade dos problemas ambientais.

É evidente o alto nível de complexidade e dificuldade que a proposta traz em seu bojo; entretanto, a nova configuração de gestão de bacia hidrográfica não pode, sob pena de não atingir os resultados esperados, deixar de compreender essa questão no contexto do gerenciamento das águas.

\section{O PROCESSO DESCENTRALIZADO}

Como já mencionado anteriormente, apesar de o Brasil contar com $12 \%$ da água potável disponível no mundo (THAME, 2000), e ocupar a $23^{a}$ posição no ranking das nações com mais água disponível no mundo (NOGUEIRA, 2004), sua distribuição não ocorre de forma uniforme, considerando a concentração da população e sua demanda em relação à água disponível. Pode-se considerar como causas principais da irregular disponibilidade, nos aspecto quantitativo e qualitativo, as seguintes: (a) modelo de desenvolvimento econômico baseado na industrialização e urbanização, gerando uma distribuição perversa de renda e um crescimento demográfico desordenado: (b) constantes e crescentes desmatamentos; (c) esquemas de irrigação mal projetados, sem

${ }^{3}$ BARROS, A. B. Organismos de bacias hidrográficas: problemas e soluções. In: MONTICELLI, J. J. (Coord.). Organismos de bacias hidrográficas. Rio de Janeiro: Secretaria de Estado de Meio Ambiente e Desenvolvimento Sustentável - SEMADS, 2002. 




nenhuma preocupação com a racionalização, ou seja, com o melhor aproveitamento; (d) visão setorializada do uso da água, privilegiando um segmento em detrimento do outro; e (e) políticas e ações relativas ao uso da água centralizadas no governo federal (FEICHAS, 2002).

Para Leal (2000) a crise hídrico-ambiental no País tem vários determinantes, entre os quais ele destaca: o modelo neoliberal de desenvolvimento econômico, marcado, sobretudo pela exploração econômica em detrimento da degradação ambiental em geral e o modelo de gerenciamento dos recursos hídricos com viés centralizador, setorializado, desarticulado, isento da participação popular, privilegiando determinados setores, notadamente o elétrico.

No que tange ao fato de as políticas e ações relativas ao uso da água estarem centralizadas no governo federal, alguns esclarecimentos devem ser feitos no sentido de fornecer subsídios para uma discussão pautada em fundamentos mais consolidados.

Segundo Franca e Neto (2006) o Estado é o único organismo capaz de iniciar processos de gestão nas proporções demandadas pelas dimensões dos recursos hídricos, tendo em vista o fato de contar com massa crítica suficiente para tanto. Ainda para esses autores, o Estado é também a única instituição munida de recursos e poderes suficientes para dar continuidade a esses processos, envolvendo, além da administração físico-financeira, a fiscalização, a punição de infrações, e o desenvolvimento de tecnologias inerentes à complexidade dos usos dos recursos hídricos.

Um dos fundamentos da Política Nacional de Recursos Hídricos (Lei n. 9.433/97) institui que a gestão dos recursos hídricos deve ser descentralizada e contar com a participação do Poder Público, dos usuários e das comunidades (Art. $1^{\circ}$ inciso VI).

A Constituição Federal no seu artigo 30, inciso I, afirma que compete aos municípios legislar sobre assuntos de interesse local. Ainda a Carta Magna, em seu artigo 23, inciso VI, evidencia que é de competência comum, associado a outros entes federados, a proteção do meio ambiente bem como o combate a poluição em qualquer de suas formas.

O município dispõe, portanto, de competência constitucional para legislar sobre o uso e ocupação do solo urbano, suburbano e rural (RIBEIRO, 2006).

De acordo com Kettelhut (2001) a necessidade da descentralização pode ser justificada, entre outros aspectos, pela dimensão continental, diversidade cultural, 


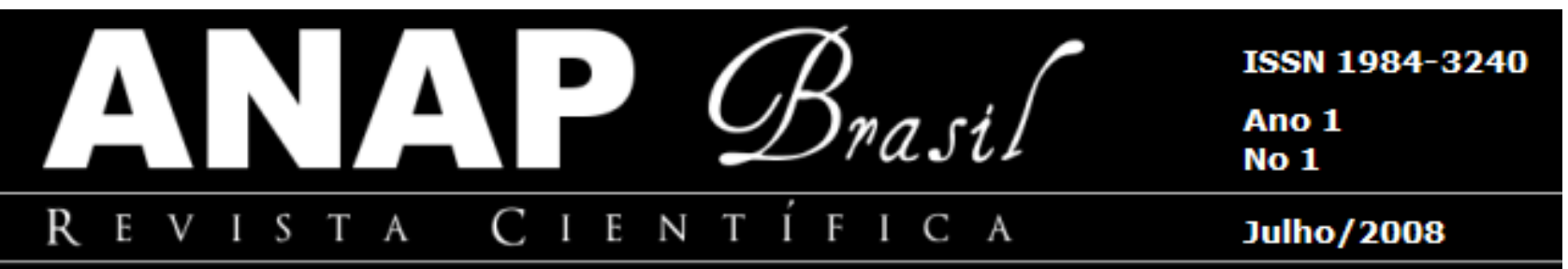

econômica, social e ambiental do Brasil. O autor menciona, ainda, a necessidade de se descentralizar também, as atividades de natureza técnica, relacionadas com a elaboração de estudos e projetos, uma vez que é importante que, desde o início dos trabalhos, possa se contar com todos os atores interessados.

Ainda, segundo Ribeiro (2006) os municípios estão aparelhados com importantes instrumentos de gestão ambiental, como planos diretores, leis orgânicas municipais, leis de uso e ocupação do solo, leis de loteamento e parcelamento, Estatuto da Cidade e demais normas urbanísticas, além da possibilidade da criação e implantação de unidades de conservação e áreas de propriedade pública direta.

Observa-se o notório avanço institucional e o suficiente aparelhamento para que o município atue de forma ordenada na gestão dos recursos naturais, notadamente dos recursos hídricos, uma vez que "hospeda uma multiplicidade de usuários de água, desde o consumidor doméstico até os usos industriais, a irrigação, e outros" (RIBEIRO, 2006, p. 39).

Não obstante a todo esse arcabouço de instrumentos de ordenamento territorial, é possível que, por deficiências administrativas - representadas, principalmente, pela falta de capacitação técnica, escassez de recursos humanos com competência específicas na elaboração, implementação, execução e gerenciamento de projetos, falta de profissionais com capacidade de articulação na gestão dos processos -, falta de vontade política de contrariar interesses opostos, falta de uma visão holística e integrada que extrapolem o período do mandato político (projetos de médio e longo prazos), os municípios, em sua grande maioria, estejam, ainda, aquém das necessidades de ação imediata nessa questão.

Dessa forma, quando se fala da capacitada exclusiva do Estado em propor ações que possam, no curto, médio e longo prazos, mitigar o processo degradatório, compreende-se a participação efetiva dos municípios, tendo em vista estar localizado nas capilaridades das ocorrências dos fatos, podendo, a partir de uma retaguarda em nível estadual e federal, contribuir efetivamente com todo o processo.

Nesse contexto, é urgente a tomada de medidas que extrapolem a instrumentalização jurídico-institucional dos municípios. Nota-se, em sua grande maioria, a ausência de competência técnica para implementar projetos, justificados pela limitação e insuficiência dos recursos financeiros. 




Nas palavras de Ribeiro (2006) "não se pode obrigar o município a cumprir determinações de outras escalas de governo e planos de recursos hídricos, mas é possível induzir comportamentos hidroconscientes por meio de incentivos".

É evidente e necessário que cada ator institucional atue em seu campo, entretanto, a relação de interdependência, a exemplo do que ocorre no campo organizacional, fundamentado no estruturalismo ${ }^{4}$, é inerente e necessária.

Na visão de Feichas (2002) a descentralização permite decisões e ações próximas dos fatos, levando-se em conta as especificidades locais. Contudo, este mesmo autor alerta para a necessidade de um rigoroso processo de coordenação a fim de não haver duplicidade de esforços, além da necessidade de manter uma visão global de todo sistema.

Assim, entende-se que, para o princípio da descentralização atingir seu objetivo, é necessário que cada ator institucional trabalhe de forma integrada e compartilhada, cuidando para que todo o processo seja "irrigado" por um fluxo de comunicação constante e pertinente, além do zelo pela não sobreposição de atuações em determinado campo em detrimento da omissão pela atuação em outro, o que geraria um desgaste e, conseqüentemente, um descrédito das instituições.

Kliksberg (1998) expõe algumas dimensões que devem ser consideradas no processo de descentralização, que serão sintetizadas a seguir:

1) Dimensão da "Transparência Institucional": diz respeito à redução de ambigüidades nas relações entre as várias esferas de poder. Clareza na definição das funções pós-descentralização, evitando as possibilidades de atritos e choques constantes.

2) Dimensão Financeira: considerado um aspecto crítico, uma vez que deve haver todo o empenho e cuidado para que a descentralização dos serviços seja acompanhada de mecanismos que permitam às entidades regionais e municipais também dispor de formas de geração e disposição dos recursos suficientes e necessários, sob pena de o processo tornar-se regressivo. Nas palavras de Karin Sthal, "conduzir uma política de descentralização sem assegurar os recursos dos

\footnotetext{
${ }^{4} \mathrm{O}$ estruturalismo envolve um estudo analítico das organizações considerando os fatores que nelas exercem influência. Essa análise ocorre de modo comparativo e globalizante, reconhecendo que a ação organizacional é integrada, interligada, interdependente e interagente. O estruturalismo tem como um dos princípios preocupar-se com o todo e com o relacionamento das partes na constituição do todo. (MORAES, A. M. P. de Introdução à Administração. 3. ed. São Paulo: Prentice Hall, 2004).
} 




municípios e sem uma compensação financeira entre as regiões ricas e as pobres, pode agravar, por acréscimo, as desigualdades sociais, fomentando, assim, uma deterioração maior do sistema estatal de serviços sociais, sobretudo nos municípios mais pobres". ${ }^{5}$

3) Dimensão da gestão institucional: refere-se à capacidade técnica-institucional de promover a gestão de todo processo, envolvendo as dimensões dos recursos (humanos e financeiros), tecnológico-gerencial, burocráticos, articulação e envolvimento de outros atores necessários no processo. Constituem-se fatores imprescindíveis no processo de planejamento, organização, direção e controle, como etapas básicas da função administrativa.

4)

Com base em estudos de campo, Raczynski (1995 apud Kliksberg, 1998) ainda adverte para o problema da perda do foco principal, tendo em vista as pressões e práticas clientelistas ser, muitas vezes, mais fortes em nível regional ou local do que em nível nacional. ${ }^{6}$

QUADRO 1. - Dimensões compreendidas no processo de descentralização.

\begin{tabular}{|c|c|c|}
\hline Dimensão & Principais Problemas & Propostas Mitigadoras \\
\hline $\begin{array}{l}\text { Transparência } \\
\text { Institucional }\end{array}$ & $\begin{array}{ll}\text { - } & \text { Excesso de } \\
& \text { ambigüidades. } \\
\text { - } & \text { Pouca clareza na } \\
& \text { definição das funções. } \\
\text { - } & \begin{array}{l}\text { Atritos e sobreposição de } \\
\text { tarefas }\end{array}\end{array}$ & $\begin{array}{l}\text { - Implementar procedimentos que } \\
\text { impeçam existência de pontos } \\
\text { ambíguos. } \\
\text { - Aumentar o nível de transparência, } \\
\text { através da simplificação de } \\
\text { procedimentos e feedback aos } \\
\text { atores envolvidos. } \\
\text { - Efetuar controle constante no intuito } \\
\text { de evitar atritos e sobreposição. } \\
\text { Corrigir imediatamente os pontos } \\
\text { conflitantes tão logo sejam } \\
\text { detectados. }\end{array}$ \\
\hline Financeira & $\begin{array}{l}\text { - } \text { Insuficiência de recursos. } \\
\text { - } \text { Ausência de formas de } \\
\text { geração e disposição de } \\
\text { recursos. } \\
\text { - Sistema inibidor das }\end{array}$ & $\begin{array}{l}\text { - Prover recursos suficientes de } \\
\text { acordo com o exigido para } \\
\text { implementação/execução planejado. } \\
\text { processo previamente planes } \\
\text { - Criar mecanismos que estimulem }\end{array}$ \\
\hline
\end{tabular}

${ }^{5}$ STHAL, Karin. Politica social em America Latina. La privatización de la crisis. Nueva Sociedad. , mai./jun., 1994.

${ }^{6}$ RACZYNSKI, Dagmar. Estrategias para combatir la probreza em América Latina. BID, CIEPLAN, 1995. 


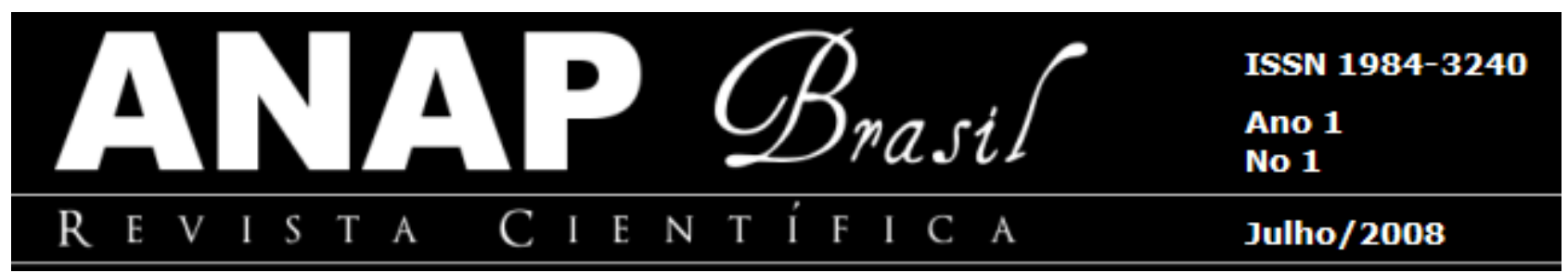

\begin{tabular}{|c|c|c|}
\hline & $\begin{array}{l}\text { iniciativas locais } \\
\text { formas alternativas. }\end{array}$ & $\begin{array}{l}\text { formas alternativas de alavancagem } \\
\text { de recursos sem reduzir o montante } \\
\text { vinculado. }\end{array}$ \\
\hline $\begin{array}{c}\text { Gestão } \\
\text { Institucional }\end{array}$ & $\begin{array}{l}\text { - } \text { Baixa capacidade } \\
\text { técnica-gerencial. } \\
\text { - Incompatibilidade entre } \\
\text { as atribuições dos } \\
\text { setores e as funções } \\
\text { propriamente } \\
\text { executadas. } \\
\text { - Falta de recursos } \\
\text { humanos qualificados. } \\
\text { - Pouco ou nenhum } \\
\text { domínio de tecnologia } \\
\text { gerencial. } \\
\text { - Incapacidade } \\
\text { desenvolver projetos. } \\
\text { - }\end{array}$ & 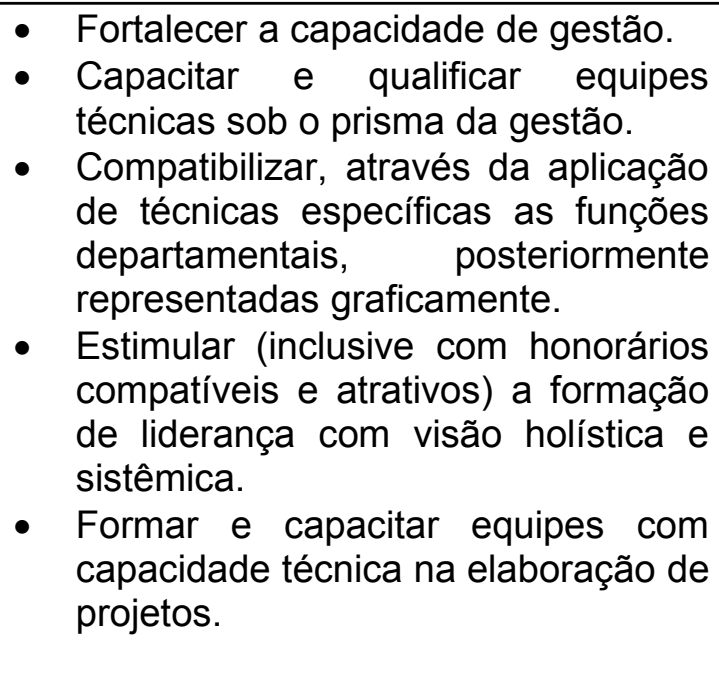 \\
\hline
\end{tabular}

Fonte: Elaborado pelo autor a partir de Klinksberg (1998).

\section{CONSIDERAÇÕES FINAIS}

Indubitavelmente, a segurança hídrica dependerá, cada vez mais, da cooperação entre as sociedades, da eliminação do desperdício e do desenvolvimento de tecnologias que contribuam para o fornecimento de água em quantidade e qualidades desejadas.

A promulgação da Lei das Águas (Lei no 9.433/97) constitui-se num importante marco na história do gerenciamento de recursos hídricos em nosso País, notadamente ao estabelecer mecanismos que possibilitem e garantam a distribuição eqüitativa do bem, priorizando o uso humano, levando-se em consideração seus aspectos quantitativos e qualitativos. Contempla, em sua essência, pontos de extrema relevância para a completa implementação e execução desse processo que visa, acima de tudo, um rigoroso cuidado com este bem escasso e imprescindível à vida.

Dessa forma, oferecer condições que subsidiem, em todos os níveis, os atores envolvidos, pode ser um caminho viável para a consolidação do processo de gerenciamento. 


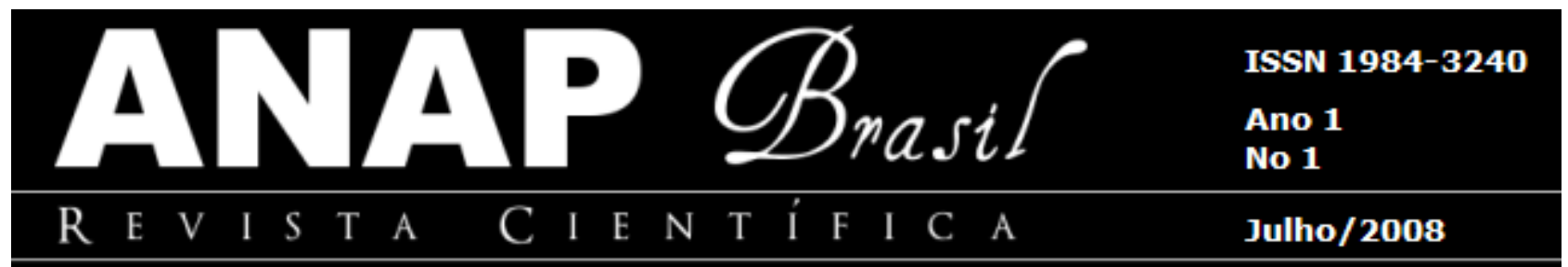

\section{REFERÊNCIAS}

AMARAL, H. K. do. Princípios de gerenciamento de recursos hídricos em bacias hidrográficas. In: SÃO PAULO (Estado). Coordenadoria de Educação Ambiental. Política e gestão de recursos hídricos no Estado de São Paulo. SMA/CEA. São Paulo: A Secretaria, 1993.

ASSUNÇÃO, F. N. A.; BURSZTYN, M. A. A. As políticas das águas no Brasil. In: III Encuentro de las águas: água, vida y desarrollo, 2001, Santiago, Chile. Anais eletrônicos... Santiago, Chile, 2001. Disponível em:

<http://www.aguabolivia.org/situacionaguaX/IIIEncAguas/contenido/tema_azul.htm.

AZEVEDO, L. G. T.; PEREIRA, J. M. G. Água no mundo. In: Plenarium, ano III, n. 3, Câmara dos Deputados, 2006.

BERBERT, C. O. O desafio das águas. In: MARTINS, R. C.; VALENCIO, N. F. L. da S. (Org.). Uso e gestão dos recursos hídricos no Brasil: desafios teóricos e políticoinstitucionais. São Carlos: RiMa, 2003.

CARDOSO, M. L. M. A democracia das águas na sua prática: o caso dos comitês de bacias hidrográficas de Minas Gerais. 2003. Tese (Doutorado em Antropologia Social) Universidade Federal do Rio de Janeiro - UFRJ, Programa de Pós-Graduação em Antropologia Social/Museu Nacional, 2003.

CAVINI, R. A. Instrumentos econômicos e gestão de águas: estudo para recuperação do reservatório Billings. 2002. Dissertação (Mestrado). Universidade Estadual de Campinas - UNICAMP, Instituto de Economia, 2002.

CRHISTOFIDIS, D. Água e agricultura. In: Plenarium, ano III, n. 3, Câmara dos Deputados, 2006.

CUNHA, S. B.; GUERRA, A. J. T. (Org.). A questão ambiental: diferentes abordagens. Rio de Janeiro: Bertrand Brasil, 2003.

FEICHAS, S. A. Q. Fatores que facilitam e dificultam o funcionamento do Comitê da Bacia Hidrográfica do Rio Paraíba do Sul. 2002. 162 f. Dissertação (Mestrado em Ciência ambiental). Universidade Federal Fluminense, Rio de Janeiro, 2002.

FERREIRA, G. L. B. V.; FERREIRA, N. B. V. Fundamentos da Política Nacional de Recursos Hídricos. In: XIII SIMPEP - Simpósio de Engenharia de Produção, 2006, Bauru. Anais... Bauru: Faculdade de Engenharia de Bauru - FEB/UNESP, Bauru, 2006. 


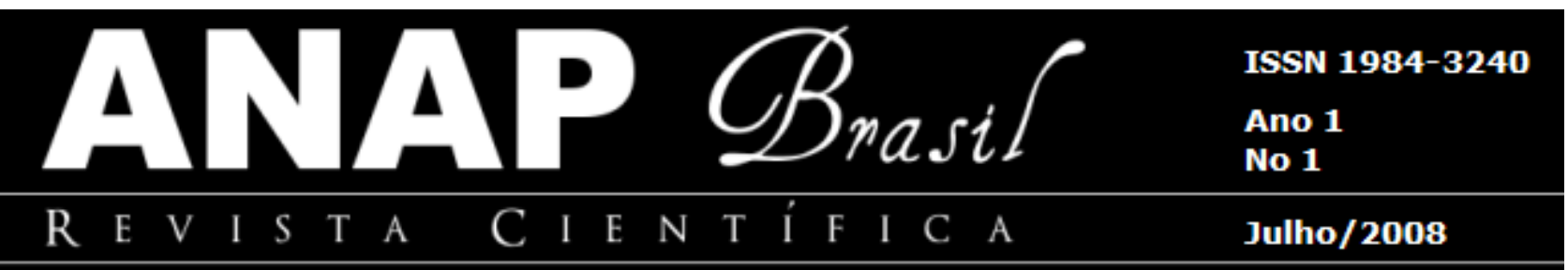

LEAL, A. C. Gestão das águas no Pontal do Paranapanema. 2000. 279 f. Tese (Doutorado em Geociências) - Universidade Estadual de Campinas, Instituto de Geociências, Campinas, 2000.

FRANCA, D. T. e NETO, A. C. Água e sociedade. In: Plenarium, ano III, n. 3, Câmara dos Deputados, 2006.

KETTELHUT, J. T. S. Os avanços da Lei das Águas. In: III Encuentro de las águas: água, vida y desarrollo, 2001, Santiago, Chile. Anais eletrônicos... Santiago, Chile, 2001. Disponível em: <http://www.aguabolivia.org/situacionaguaX/IIIEncAguas/contenido/tema_azul.htm.

KLIKSBERG, B. Repensando o Estado para o desenvolvimento social: superando dogmas e convencionalismos. São Paulo: Cortez, 1998.

MOREIRA, M. M. M. A. A Política Nacional de Recursos Hídricos: avanços recentes e novos desafios. In: FELICIDADE, N.; MARTINS, R. C.; LEME, A. A. (Org.). Uso e gestão dos recursos hídricos no Brasil: velhos e novos desafios para a cidadania. 2. ed. São Carlos: RiMa, 2004.

NOGUEIRA, D. Relação entre capital social e agenda na gestão de recursos hídricos: um estudo de caso do Comitê Rio das Velhas, Minas Gerais, Brasil. Brasília, DF, [2001]. Disponível em http://www.marcadagua.org.br/relacao-capita-social-agendadaniela.pdf Acesso em 28 mar. 2008.

NOGUEIRA, D. O uso da água na agricultura. In: THAME, A. C. de M. (org.). A cobrança pelo uso da água na agricultura. São Paulo: IQUAL Editora, 2004.

NOVAES, R. C. Cooperação e conflito nas águas da Bacia do Rio Paraíba do Sul: limites e possibilidades de gestão integrada no "trecho paulista". 2006. (Doutorado em Ciência Ambiental). Universidade de São Paulo - USP, Programa de Pós-Graduação em Ciência Ambiental - PROCAM, São Paulo, 2006.

OLIVEIRA, E. C. de. Considerações teóricas sobre o comitê de bacia hidrográfica: um estudo preliminar sobre o desafio do processo participativo. In: VIII Semana de Geografia e III Encontro de Estudantes de Licenciatura em Geografia, 2007, Presidente Prudente. Anais... Presidente Prudente: Faculdade de Ciências e Tecnologia/UNESP, 2007.

PETRELLA, R. O manifesto da água: argumentos para um contrato mundial. Petrópolis, RJ: Vozes, 2002.

REBOUÇAS, A. Uso inteligente da água. São Paulo: Escrituras Editora, 2004.

RIBEIRO, M. A. Hidratando a gestão ambiental. In: Plenarium, ano III, n. 3, Câmara dos Deputados, 2006. 


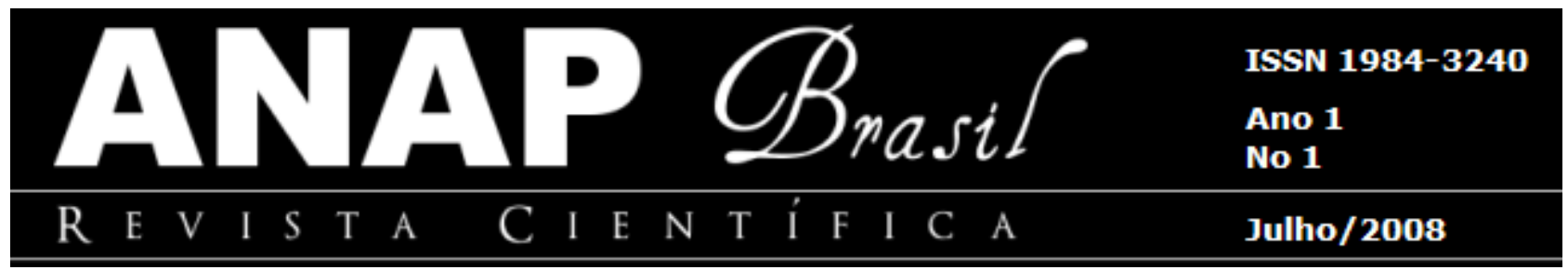

SÃO PAULO (Estado). Secretaria do Meio Ambiente. Coordenadoria de Planejamento Ambiental Estratégico e Educação Ambiental. Gestão participativa das águas. São Paulo: SMA/CPLEA, 2004.

SETTI, A. A. et all. Introdução ao gerenciamento de recursos hídricos. Brasília: Agência Nacional de Energia Elétrica (ANEEL); Agência Nacional de Águas (ANA), 2001.

SILVA, E. R. O curso da água na história: simbologia, moralidade e a gestão de recursos hídricos. 1998. Tese (Doutorado). Fundação Oswaldo Cruz/Escola Nacional de Saúde Pública, Rio de Janeiro, 1998.

THAME, A. C. de M. Conclusão. In: THAME, A. C. de M. (Org.). A cobrança pelo uso da água na agricultura. Embu, São Paulo: IQUAL Editora, 2004.

TUNDISI, J. G. Água no século XXI: enfrentando a escassez. 2. ed. São Carlos: RiMa, 2005. 